\title{
Treatment of an uncommon case of recurrent cervical spine aneurismal bone cyst, using radiotherapy: a case report
}

\begin{abstract}
Aneurismal bone cysts are uncommon in spines, constitute of only $15 \%$ of all spine bone tumors. They occurs the most common in the thoracic spine and the least in the cervical ones. Although the mainstay of the treatment is surgery, but the management of recurrent cases especially in the cervical spine is challenging, as a result of complicated surgery in this area. The present case provides information regarding treatment of a recurrent cervical spine $\mathrm{ABC}$, using radiotherapy.
\end{abstract}

Keywords: aneurismal bone cyst, radiotherapy,spine bone tumor

\author{
Volume 5 Issue I - 2016

\section{Sasan Razmjoo, Maedeh Berahman, Somaye Barihi, Shole Arvandi, Hojjatollah Shahbazian, Seyed Mohammad Hosseini, Maryam Feli Department of Radiotherapy and Oncology, Ahvaz Jundishapur University of Medical Sciences, Iran}

\begin{abstract}
Correspondence: Maryam Feli, Department of Radiotherapy and Oncology, Ahvaz Jundishapur University of Medical Sciences, Golestan Boulevard, Ahvaz, Iran, Tel 9.86I34E+ I I, Fax
\end{abstract} 9.86134E+I I,Email hjalaeia@umn.edu

Received: January 01, 1970 | Published: June 14, 2016

\section{Introduction}

Aneurismal bone cysts $(\mathrm{ABC})$ constitute of $1-2.5 \%$ of primary bone tumors, despite their benign nature, they can be locally aggressive and expanding. ${ }^{1}$ Most of the cases occur in the first and second decade of life, with the mean age of 14 to 16 years at diagnosis. These highly vascular, relatively rare lesions mostly affect long bones followed by spines with slightly female predominance. The lumbar spine is the most frequent site, followed by thoracic, cervical and sacral ones. ${ }^{2}$

The most common feature of $\mathrm{ABC}$ is local pain, which could be associated with a palpable tender mass. Neurologic involvement is not common, but progression of the disease could lead to paraplegia and cord compression. ${ }^{3,4}$

Treatment options include curettage, subtotal or total resection with or without reconstruction, schlerotherapy and radiotherapy. Despite all these treatments recurrences particularly after subtotal resection is not uncommon. Treatment of recurrent spine $\mathrm{ABC}$ is a clinical challenge and could result in serious complications. ${ }^{5,6}$

In this article we present an uncommon case of recurrent multilevel aneurismal bone cyst of cervical spine.

\section{Case presentation}

A23 years old lady was referred to our clinical oncology department with a history of neck mass. Her symptoms back to over one year ago with a large, non-tender, firm, gradually progressive swelling over the right side of her neck. The pain was constant which radiating to shoulder. She had developed upper extremity weakness through months. She had no history of trauma or co morbid condition. Her general physical examination was normal. Neurological examination revealed decreased upper limb muscle force by the score of $2 / 5$.

Her neck ultrasound showed a thick irregular wall hypoechoeic soft tissue mass $24 \times 20 \mathrm{~mm}$ size in right cervical portion with cystic change and internal echo. Computed tomogram of spine showed $35 \times 30 \mathrm{~mm}$ heterogeneous enhancing mass in right para vertebral area, extending into right $\mathrm{C} 5$-C6 foramina. Craniospinal magnetic resonance imaging showed a heterogeneous mass lesion $35 \times 35 \times 45 \mathrm{~mm}$ size in right side of neck at level of C5-C6 with extension into right side neural foramen, which caused expansion without destruction. Mentioned mass showed cystic component (Figure 1).

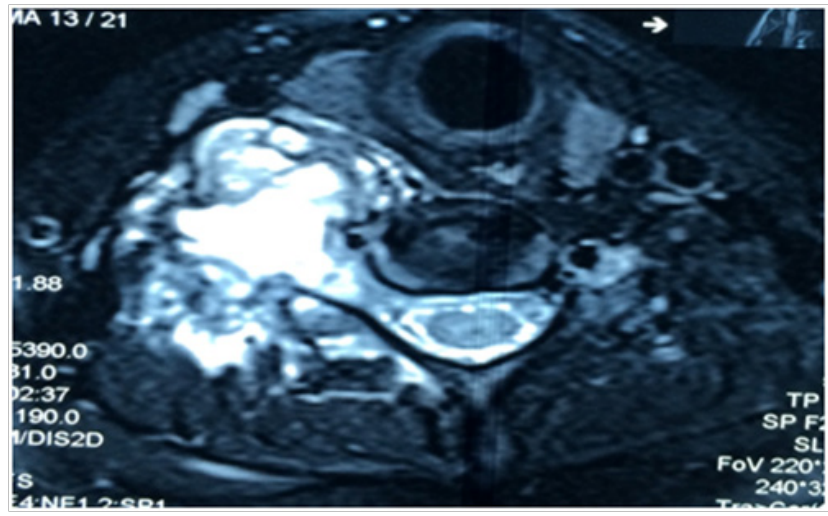

Figure I Pre-operation MRI.

Radical resection of tumor, foramenectomy of $\mathrm{C} 5-\mathrm{C} 6$ and resection of tumor, as well as, C3-C4-C5-C6 posterior arthrodesis with lateral mass screw and posterolateral fusion with all grafting was done.

In the postoperative period, her recovery was uneventful. Microscopic examination showed blood filled spaces which lined by spindle-shaped cells admixed with osteocalst-type giant cells, set in vascularized mildly inflamed fibrotic stroma. Multiple fibrous septa which displayed areas of new bone formation were identified. These pathologic findings were compatible with $\mathrm{ABC}$.

Two months later she was re-admitted with a painful recurrent mass measuring $35 \times 20 \mathrm{~mm}$ at the same location (Figure 2). She underwent curettage, and referred for radiotherapy one week later. She received external beam radiotherapy using a 6 megavoltage photon beam on a linear accelerator, with two parallel-opposed lateral rectangular field 
size of $8.5 \times 7 \mathrm{~cm}$ (length $\mathrm{x}$ width ). In a continuous course, she treated 5 days a week with standard daily fractions of $2 \mathrm{~Gy}$ up to a total dose of $26 \mathrm{~Gy}$.

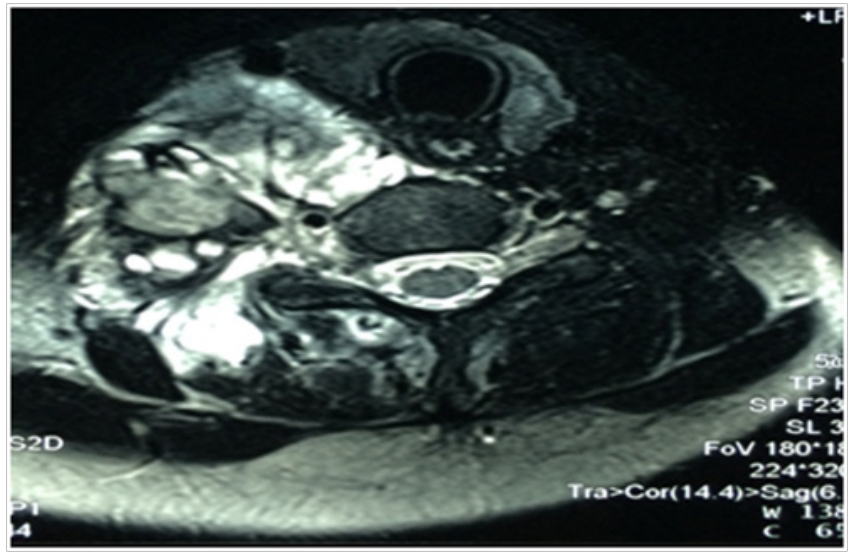

Figure 2 External beam radiotherapy.

She had complete relief of her symptoms within 2 weeks of completing radiotherapy. On her last visit, 36 months after radiotherapy, she was symptom free and computed tomogram of neck after 36 months showed no evidence of recurrence (Figure 3 ).

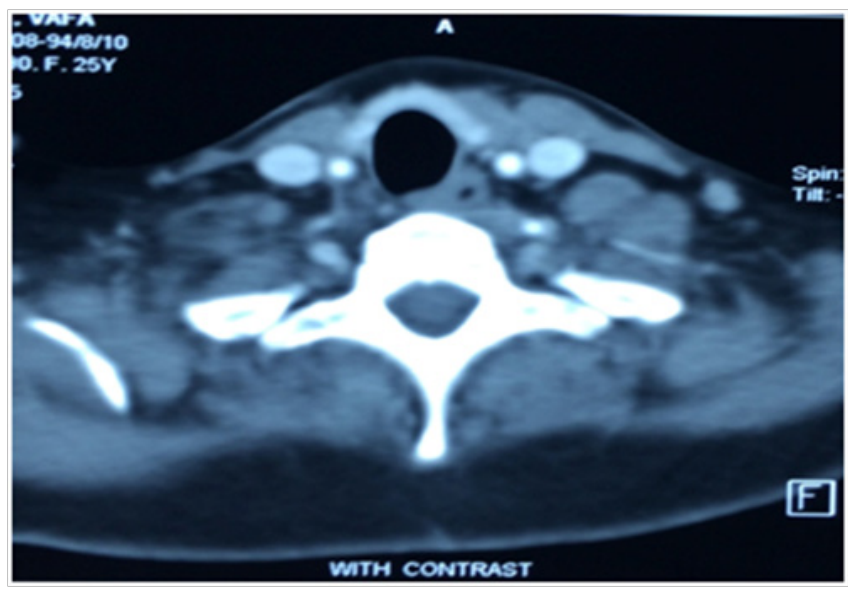

Figure 3 Post operation CT scan after 36 months follow up.

\section{Discussion}

Aneurysmal Bone Cysts compromise of approximately $15 \%$ of primary spine tumors, which more affect the lumbar and thoracic spines than cervical ones. Cervical ABCs account for $5 \%$ of all spine ABCs. Spine ABCs affect posterior elements and the pedicle more than anterior elements and the lesion usually involve only one level, but multilevel cases have been reported as well. ${ }^{7}$ In almost $30 \%$ of patients, the tumour intersects to the adjacent vertebrae through surrounding soft tissue mass. ${ }^{3,4}$

Our patient presented as a tender lump on the anterior right side of her neck and after evaluations diagnosed as multilevel cervical ABC.

The accurate pathogenesis of the disease is not well known. Some theories suggested these lesions are preceded by traumatic fracture, subperiosteal hematoma or pre-existing bone diseases, including fibrous dysplasia, giant cell tumor and non-ossifying fibroma. ${ }^{1,8}$ As mentioned above, in this case there was no history of trauma or previous bone disease.
Microscopic pathological findings of $\mathrm{ABC}$ show numerous cavernous blood filled cavities separated by fibrous septa. These cavities are not true vascular channels, since they lack lining by endothelium. ${ }^{1,9}$ As it seen in the present case osteoclast-type giant cells in fibrotic stroma and new bone formation, would be found on microscopic specimen.

Preoperative CT scan is reliable for detecting the bone destruction and the integrity of cortical bone. Besides, it is useful for surgical planning and instrumented fusion based on the tumour size and extent. The MR imaging modality is better evaluating the full extent of bone and soft tissue involvement and degree of neural element compression. In addition, it would show the characteristic appearance of cysts containing fluid-fluid interfaces on T2-weighted MR imaging.

In the present case both MR and CT was prior to surgery. ${ }^{2,10}$ While $\mathrm{ABCs}$ are benign, non-neoplastic phenomena, their rapid growth could result in extensive bone destruction and neurologic involvement. Consequently, the aggressive therapy is crucial.

The optimal treatment of spine $\mathrm{ABC}$ is still controversial. ${ }^{6}$ Because of the unique anatomy and function of spines, surgical accessibility is complicated.

Despite the fact that complete resection and reconstruction is the treatment of choice in $\mathrm{ABC}$, recurrence would occur even after such an extensive operation. Management of the recurrent ABC in cervical spine could be challenging, since re-resection would result in severe blood loss, spine instability, neurologic complication, and even paralysis.

Since adequate surgical resection of recurrent cervical spine $\mathrm{ABC}$ would result in significant morbidity or poor cosmetic outcome, alternatively radiotherapy can be used.

Feigenberg et al. ${ }^{11}$ used megavoltage radiotherapy, using the prescribed dose of 26-30 Gy, for the local treatment of spine ABC in 19 cases. They revealed that modern-day RT could play a role in the treatment of recurrent or inoperable spine $\mathrm{ABC}$ with minimum toxicity. Besides, it is useful in pain relief of such patients. They followed patients at the minimum of 20 months and did not detect any sign of complication or recurrence. ${ }^{11}$ In 2006 Kumar et al. ${ }^{12}$ reported a case of recurrent $\mathrm{ABC}$ on temporal bone, which were treated with $31.5 \mathrm{~Gy}$ in 18 fractions and found reasonable outcome. ${ }^{12} \mathrm{Zhu}$ et al. ${ }^{13}$ evaluated the long-term effectiveness of RT as an adjuvant or alternative treatment for $\mathrm{ABC}$. They reviewed the medical records of 12 patients who received RT at the mean dose of 30.15 Gy and followed them at least 3 years. No patient showed RT complications or recurrence. ${ }^{13}$

According to previous reports we successfully treated a recurrent cervical spine $\mathrm{ABC}$ after subtotal resection, using RT as an adjuvant, since the total resection wasn't possible and the rate of second recurrence was high. She remained recurrence and symptom-free 36 months after the end of treatment.

More investigations are required to evaluate the role of radiotherapy as an adjuvant treatment modality after subtotal resection or curettage of spine $\mathrm{ABC}$, which could decrease the subsequent recurrences and re-resection morbidity.

\section{References}

1. Ameli NO, Abbassioun K, Saleh H, et al. Aneurysmal bone cyst of the spine. Report of 17 cases. J Neurosurg. 1985;63(5):685-690. 
2. Kleuver MD, van der Heul RO, Veraart BE. Aneurysmal bone cyst of the spine: 31 cases and the importance of the surgical approach. J Pediatr Orthop B. 1988;7(4):286-292.

3. Papagelopoulos PJ, Currier BL, Galanis EC, et al. Vertebra plana of the lumbar spine caused by an aneurysmal bone cyst: a case report. Am J Orthop (Belle Mead NJ). 1999;28(2):119-124.

4. Raftopoulos C, Hurrel A, Ticket L, et al. Total recuperation in a case of sudden total paraplegia due to aneurysmal bone cyst of the thoracic spine. Childs Nerv cyst.1994;90(7):464-467

5. Clough JR, Price CH. Aneurysmal bone cyst: pathogenesis and long term results of treatment. Clin Orthop Res. 1973;97:52-63.

6. Turker RJ, Mardjetko S, LubickyJ. Aneurysmal bone cysts of the spine: excision and stabilization. J Pediatr Orthop.1998;18(2):209-213.

7. Capanna R, Albisinni U, Picci P, et al. Aneurysmal bone cyst of the spine. J Bone Joint Surg Am. 1985;67(4):527-531.
8. Dabezies EJ, D'Ambrosia RD, Chuinard RG, et al. Aneurysmal bone cyst after fracture. A report of three cases. J Bone Joint Surg Am. 1982;64(4):617-621.

9. Dahlin DC, McLeod RA. Aneurysmal bone cyst and other nonneoplastic conditions. Skeletal Radiol. 1982;8(4):243-250.

10. Chan MS, Wong YC, Yuen MK, et al. Spinal aneurysmal bone cyst causing acute cord compression without vertebral collapse: CT and MRI findings. Pediatr Radiol. 2002;32:601-604

11. Feigenberg SJ, Marcus RB, Zlotecki RA, et al. Megavoltage radiotherapy for aneurysmal bone cysts. Int J Radiat Oncol Biol Phys. 2001;49(5):1243-1247.

12. Kumar $\mathrm{P}$, Singh $\mathrm{S}$, Phadke RV, et al. Role of radiotherapy in a recurrent aneurysmal bone cyst of the temporal bone: case report. Neurosurgery. 2006;58(3):E584.

13. Zhu S, Hitchcock KE, Mendenhall WM. Radiation Therapy for Aneurysmal Bone Cysts. Am J Clin Oncol. 2015. 